\title{
IDADE Pb-Pb E ASPECTOS PETROLÓGICOS DA MINERALIZAÇÃO EM SODALITA AZUL DO MACIÇO NEFELINA-SIENITICO ITARANTIM, SUL DO ESTADO DA BAHIA
}

\author{
MARIA DE LOURDES DA SILVA ROSA ${ }^{1,2}$, HERBET CONCEIÇÃO ${ }^{2,3}$, MOACIR JOSÉ BUENANO \\ MACAMBIRA ${ }^{4}$, MOACYR MOURA MARINHO ${ }^{2,5}$, MÔNICA PRISGSHEIM DA CUNHA ${ }^{2,3} \&$ \\ RITA CUNHA LEAL MENEZES ${ }^{2,3}$
}

\begin{abstract}
Pb-PbAGEAND PETROOLOGICALASPECTS OF THE BLUE SODALITE MINERALIZATION OF THE ITARANTIM NEPHELINE-SYENITE MASSIF. SOUTHERN STATE OF BAHIA The Itarantim nepheline-syenite massif ( $\left.220 \mathrm{~km}^{2}\right)$ is a late proterozoic intrusion $(727 \pm 30 \mathrm{Ma}$; Rb-Sr) of the southern region of the State of Bahia. It is mostly constituted by nepheline-bearing syenites, with biotite or aegirine, and by alkaline dykes. The dykes are more abundant in the biotite-nepheline-syenites and are the most evolved rocks of the massif. Recently, a blue sodalite-syenite dyke has been identified in the southwest part of the massif, hosted by biotite-nepheline syenites. The blue syenites have been exploited as dimension stone. The dyke has magmatic sodalite that crystallized between $720 \pm 9 \mathrm{Ma}$ and $732 \pm 24 \mathrm{Ma}\left(\mathrm{Pb}-\mathrm{Pb}_{\mathrm{K}}\right)$, and cuts the magmatic foliation of the host syenite, imprinting a metasomatism with sodalite formation. Petrographic data indicate that the magmatic sodalite formed during the late stages by a volatile rich magma (500-600 $\mathrm{C}$ ). The high contents (ppm) of $\mathrm{Zr}(>5,000)$, Hf (141), Ta (169), U (74) and F (1200) of the blue syenite suggest that it represents a highly evolved product from differentiation of the nepheline-syenitic magma.
\end{abstract}

Keywords: $\mathrm{Pb}-\mathrm{Pb}$ age, blue sodalite, Itarantim Nepheline-Syenitic Massif.

Resumo O Maciço Nefelina-Sienítico Itarantim $\left(220 \mathrm{~km}^{2}\right)$ constitui uma intrusão brasiliana (idade Rb-Sr de $\left.727 \pm 30 \mathrm{Ma}\right)$ localizada no extremo sul do alinhamento de rochas alcalinas existente no sul do Estado da Bahia. Ele é constituído essencialmente por nefelinasienitos com biotita ou egirina e por diques alcalinos, mais abundantes no biotita-nefelina-sienito. Estes diques constituem as rochas mais evoluídas deste maciço. Recentemente foi identificado um dique de sodalita-sienito de cor azul encaixado no biotita-nefelinasienito, localizado na região sudoeste do maciço e que está sendo explorado como rocha ornamental. Este dique, portador de sodalita magmática e cuja idade de cristalização está compreendida entre $720 \pm 9 \mathrm{Ma} \mathrm{e} 732 \pm 24 \mathrm{Ma}\left(\mathrm{Pb}-\mathrm{Pb}_{\mathrm{Zr}}\right)$, trunca a foliação magmática do sienito encaixante e provoca formação de sodalita metassomática. Os dados petrográficos indicam que a sodalita magmática do dique forma-se no final da cristalização $\left(500-600^{\circ} \mathrm{C}\right)$ de um magma particularmente rico em fluidos. Os elevados conteúdos em ppm de $\mathrm{Zr}$ (>5.000). Hf (141), Ta (169), U (74) e F (1200) obtidos para os sienitos azuis estudados sugerem que eles representem produtos fortemente evoluídos da diferenciação do magma nefelina-sienítico.

Palavras-chave: Idade Pb-Pb, sodalita azul, Maciço Nefelina-Sienítico Itarantim.

INTRODUÇão Na região sul do Estado da Bahia tem-se explorado nos últimos 40 anos rochas sieníticas de cor azul, que no mercado de rochas ornamentais são nomeadas de "Azul-Bahia" ou "Granito-Azul". A cor azul nestas rochas resulta da presença de sodalita, e um bloco desta rocha é comercializado na mina por US $\$ 500 / \mathrm{m}^{3}$ (dólar americano), quanto o preço final do sienito azul pode chegar a US $\$ 5.000 / \mathrm{m}^{3}$ (Spínola 2003).

Os sienitos azuis são esporádicos no interior dos maciços nefelina-sieníticos e constituem corpos irregulares e de pequenas dimensões $\left(<3 \mathrm{~km}^{2}\right)$. Atualmente as explorações mais importantes de sienitos azuis localizam-se nos maciços Itajú do Colônia, Potiraguá, Itarantim e no Complexo Alcalino Floresta Azul.

Os estudos desenvolvidos até agora (Fujimori, 1978, Cunha et al. 2002, Menezes et al. 2002) têm demonstrado que os sienitos azuis correspondem a uma fácies pegmatítica. Menezes et al. (2002) e Cunha et al. (2002) têm descrito, nos vários maciços por eles estudados, que o aparecimento da sodalita se processa as custas de nefelina-sienitos e por ação de processo metassomático.

As idades K-Are Ar-Ar em minerais (Cordani et al. 1974, Bernat et al. 1977) e isócronas $\mathrm{Rb}-\mathrm{Sr}$, em rochas (Brito Neves et al. 1980, Martins \& Santos 1993), de sítios mineralizados em sodalita azul têm revelado valores de 429 Ma até 732 Ma. Determinações geocronológicas recentes, efetuadas pelo método $\mathrm{Pb}-\mathrm{Pb}$ por evaporação de monocristais de zircão, em rochas sieníticas de maciços que hospedam mineralizações em sodalita azul forneceram idades entre 688 e $739 \mathrm{Ma}$ (Corrêa Gomes 2000, Rosa et al. 2002. 2003).

A presença de cristais de zircão nos sienitos azuis em uma mina em exploração no Maciço Nefelina-Sienítico Itarantim fornece a primeira oportunidade de se datar esta mineralização utilizando-se do método $\mathrm{Pb}-\mathrm{Pb}$ em zircão. Assim, os objetivos deste trabalho são os de apresentar a idade $\mathrm{Pb}-\mathrm{Pb}$ por evaporação de

\footnotetext{
I - Pesquisadora do CNPq - Desenvolvimento Científico Regional (DCR). (lourdes@cpgg.ufba.br)

2 - Laboratório de Petrologia aplicalda à Pesquisa Mineral, Instituto de Geociências. UFBA. Rua Caetano Moura, 123, Federação, CEP: 40201-340,

Salvador-BA (herbet@ufba.br, mpunha@ufba.br, menezesrita@hotmail.com)

3 - Curso de Pós-Graduação em Geologia - UFBA

4 - Cento de Geociências, UFPa. Caixa Postal 1611. CEP: 66075-900, Belém-PA (moamac@ufpa.br)

5 - Companhia Baiana de Pesquisa Mineral, 4a Avenida, 460, Centro Administrativo da Bahia, CEP: 41750-300, Salvador-BA (cbpmdt@cbpm.com.br)
} 
monocristais de zircão e, associado a dados geológicos, petrográficos e litogeoquímicos igualmente obtidos, discutir a gênese dos sodalita-sienitos azuis deste sítio mineralizado.

\section{PROVÍNCIA ALCALINA DOSUL DOESTADODA BAHIA}

A Província Alcalina do Sul do Estado da Bahia (PASEBA), como definida por Silva Filho et al. (1976), reune um conjunto de quatro intrusões maiores (Itabuna, Complexo Floresta Azul, Araras e Itarantim), cerca de 20 stocks e, algumas centenas de diques. Todo este conjunto encontra-se distribuído em uma faixa de $8.500 \mathrm{~km}^{2}$ orientada NE-SW por 140 km (Fig. 1). Os dados geocronológicos mais recentes (Teixeira et al. 1997, Corrêa Gomes 2000, Rosa et al. 2002, 2003) permitem inferir que o magmatismo da PASEBA foi ativo durante aproximadamente $60 \mathrm{Ma}$.

Os corpos alcalinos da PASEBA são intrusivos em rochas arqueano-paleoproterozóicas. Em sua parte nordeste, os maciços alcalinos são intrusivos em rochas granulíticas e a sudoeste, rochas gnáissico-migmatíticas (Fig. 1). A distribuição alinhada (NESW) dos corpos da PASEBA é interpretada por Mascarenhas (1979) como devida a controle tectônico regional e vários trabaIhos posteriores ratificam esta hipótese (e.g. Lima et al. 1981, Corrêa Gomes 2000).

Os dados litogeoquímicos disponíveis sobre as rochas alcalinas da PASEBA (Rosa et al. 2003 e referências lá citadas) permitem caracterizar este magmatismo como alcalino sub-saturado em sílica e miasquítico, de ambiente intraplaca continental similar aos de rift.

MACIÇO NEFELINA-SIENÍTICO ITARANTIM O Maciço Nefelina-Sienítico Itarantim (MNSI), cartografado por Barbosa de Deus et al. (1976) e Oliveira (2003), é um corpo com forma de pêra, com aproximadamente $220 \mathrm{~km}^{2}$, intrusivo em rochas gnáissicomigmatíticas arqueano-paleoproterozóicas. Esta intrusão trunca as estruturas regionais, sendo parcialmente retrabalhada por falhas tardias (Fig. 2).

Os estudos realizados por Cordani et al. (1974) e Bernat et al. (1977) forneceram para o MNSI idades K-Are Ar-Arem minerais variando de $474 \mathrm{Ma}$ até $546 \mathrm{Ma}$. Rosa et al. (2002) obtiveram uma isócrona $\mathrm{Rb}-\mathrm{Sr}$ em rochas cogenéticas com idade de $727 \pm 30 \mathrm{Ma}$ $\left({ }^{87} \mathrm{Sr} /{ }^{86} \mathrm{Sr}_{\text {inicial }}=0,7031 \pm 0,0002, \mathrm{MSWD}=1,5\right)$. Esta idade é interpretada por estes autores como a da cristalização deste maciço.

Segundo Oliveira (2003), o MNSI é constituído por 6 grupos de rochas: fenitos, aegiria-nefelina-sienito, biotita-nefelina-sienito, diques fonolíticos, pegmatitos nefelina-sieníticos e diques basálticos.

Os fenitos ocorrem como uma auréola descontínua ao maciço (Fig. 2). Nestes fenitos as estruturas pretéritas metamórficas (foliação, bandamentos e dobras) tendem a desaparecer nas proximidades da intrusão, a sua mineralogia é gradualmente substituída por feldspato alcalino, aegirina e anfíbólio sódico, e suas composições evoluem de granitos para quartzo-sienitos até sienitos alcalinos. Alguns xenólitos de gnaisses, com dezenas de metros, foram identificados na parte central deste maciço por Oliveira (2003). Nestes xenólitos, as estruturas, texturas e mineralogia originais foram totalmente destruídas. Eles apresentam-se como rochas isotrópicas, com grandes porfiroblástos de anfibólio sódico e de magnetita que se encontram imersos em uma matriz fortemente poligonizada e constituída por microclina, albita, quartzo, calcita, aegirina e titanita.

Os sienitos do MNSI apresentam granulação média a grossa, ocasionalmente pegmatítica, e exibem estrutura de fluxo magmático

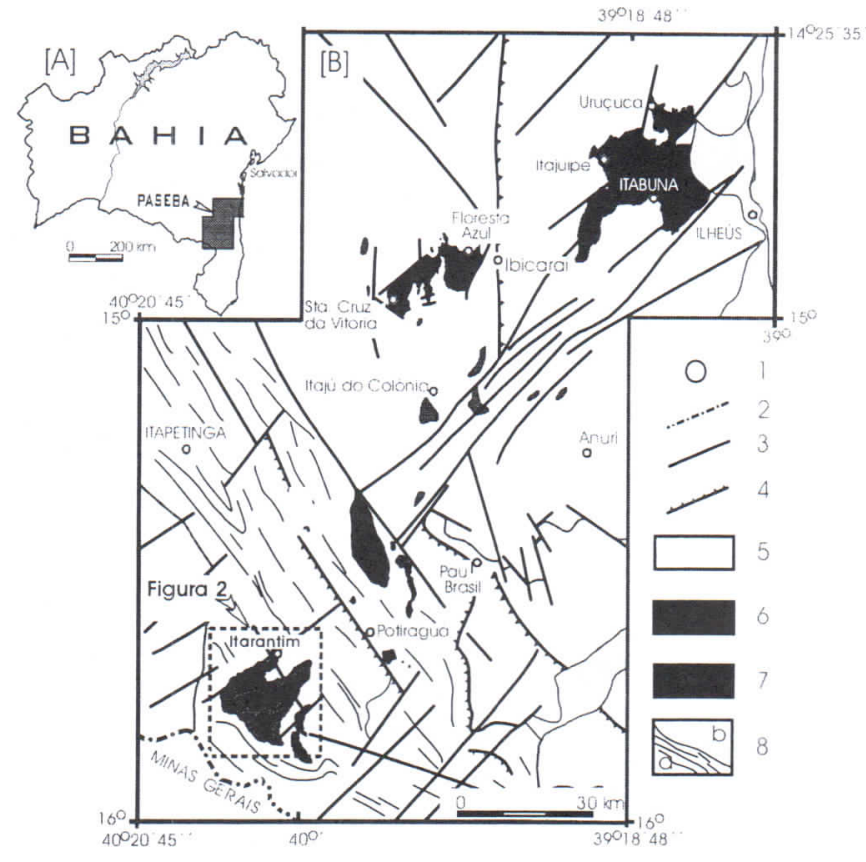

Figura 1 - Localização da área de ocorrência das rochas alcalinas neoproteróicas do sul do Estado da Bahia [A]. Mapa geológico simplificado da Província Alcalina do Sul do Estado da Bahia (Rosa et al. 2003) [B]. Cidades [1], limite estadual [2], falha e fratura [3], falha de cavalgamento [4], sedimentos recentes [5], maciços alcalinos neoproterozóicos [6], metassedimentos mesoproterozóicos [7], rochas arqueano-paleoproterozóicas [8, $a=$ granulitos e $b=$ granulitos e gnaisses $]$.

marcada pelo alinhamento dos prismas de feldspato alcalino e dos minerais máficos. Os dois conjuntos de nefelina-sienitos presentes no MNSI exibem contatos gradacionais entre si (Barbosa de Deus et al. 1976, Oliveira 2003). O aegirina-nefelina-sienito localiza-se na parte norte do maciço e o biotita-nefelina-sienito na porção sul (Fig. 2).

O aegirina-nefelina-sienito é marrom-escuro, onde a nefelina, macroscopicamente verde, cristalizou-se após o feldspato alcalino (pertítico e antipertítico), ocupando os interstícios juntamente com cristais de aegirina-augita, aegirina, apatita e minerais opacos. A aegirina cristalizou-se após a nefelina e ocorre como cristais anédricos ou como coroa nos cristais de aegirina-augita e, ocasionalmente, em torno de alguns cristais de magnetita.

O biotita-nefelina-sienito é esbranquiçado a branco. A nefelina é mais precoce que nos sienitos com aegirina. Os feldspatos alcalinos subédricos antipertíticos dominam sobre os pertíticos e a biotita marrom subédrica é o máfico dominante. Os minerais acessórios são apatita, minerais opacos e hornblenda. Aegirina, calcita e titanita estão ocasionalmente presentes.

Os estudos de Oliveira (2003), com base em dados petrográficos e litogeoquímicos, apontam que os dois tipos de sienito do MNSI são cogenéticos e que o biotita-nefelina-sienito representa um termo mais evoluído que o aegirina-nefelina-sienito. Os elevados valores em ppm de $\mathrm{Nb}$ (90-200) e Y (40-100) foram interpretados por este mesmo autor como a expressão de um magma anorogênico associado a ambiente de rift. Estas rochas apresentam valores de $\varepsilon N d_{T}$ positivos $(1,5-2,6)$ e baixas razões iniciais de $\mathrm{Sr}(0,7029-0,7031)$ indicativas de fonte no manto (Oliveira 2003). 


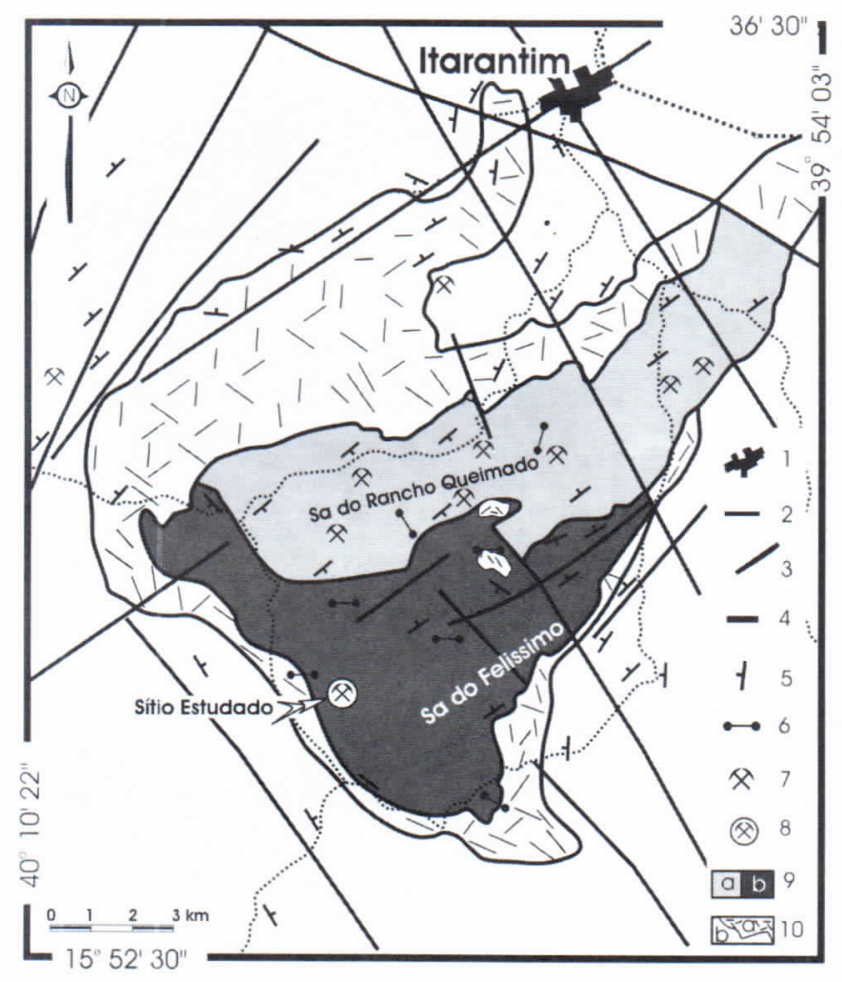

Figura 2 - Mapa geológico simplificado do Maciço NefelinaSienítico Itarantim após Barbosa de Deus et al. (1976) e Oliveira (2003). Cidade [1], estrada [2], contato geológico [3], falha e fratura [4], foliação [5], dique [6], pedreiras em explotação de rocha ornamental [7], pedreira objeto deste estudo [8], Maciço Nefelina-Sienítico Itarantim [9, a = aegirina-nefelina-sienito e $b=$ biotita-nefelina-sienito], rochas gnaíssico-migmatíticas do embasamento [10, $a=$ fenitizadas e $b=$ não transformadas].

Diques fonolíticos e pegmatitos alcalinos correm de forma esporádica nos dois conjuntos de sienitos, sendo mais abundantes, embora com menores dimensões, nos biotita-nefelina-sienitos. Os diques básicos presentes são corpos tabulares com espessuras inferiores a três metros, geralmente muito alterados e mais frequientes na parte sudeste do MNSI.

MÉTODOS ANALÍTICOS As 10 amostras selecionadas para o estudo do sítio mineralizado foram coletadas em uma pedreira onde se explota sodalita-sienito azul e todas elas foram inicialmente estudadas à luz do microscópio petrográfico. Em 6 destas amostras, com granulação fanerítica média e consideradas representativas das fácies petrográficas estudadas, analisou-se elementos maiores e alguns traços, inclusive os elementos terras raras (ETR). Estas análises químicas foram efetuadas pelo consórcio Geosol/ Lakefield Ltda.

As amostras 2034 e 2035 (coordenadas UTM 379141-8251337 e 379146-8251340), que correspondem a sodalita-sienitos, foram selecionadas para determinação geocronológica pelo método $\mathrm{Pb}$ $\mathrm{Pb}$ por evaporação em monocristal de zircão. Devido ao tamanho centimétrico (1-3 cm) dos cristais de zircão a extração foi efetuada manualmente, após a desagregação da rocha. Como estes cristais apresentavam-se com grande número de fraturas tardias, foram recuperados apenas uns poucos cristais perfeitos. Tanto os cristais quanto os fragmentos obtidos foram analisados a lupa binocular, objetivando determinar a tipologia segundo o método de Pupin (1980) e selecionar os melhores grãos, sem fraturas e inclusões, para serem analisados. Para que pudessem ser encaixados no filamento "canoa", estes grãos tiveram suas dimensões reduzidas a uma granulometria inferior a $0,6 \mathrm{~mm}$.

As determinações isotópicas de $\mathrm{Pb}$ foram realizadas no Laboratório de Geologia Isotópica da Universidade Federal do Pará, segundo a metodologia de evaporação de Köber (1987). As análises foram efetuadas em um espectrômetro de massa FINNIGAN MAT 262, onde a intensidade dos diferentes isótopos de $\mathrm{Pb}$ emitidos foi medida por um contador de íons, sendo que cada conjunto de 10 varreduras define um bloco de leitura. Com a média das razões ${ }^{207} \mathrm{~Pb} /{ }^{206} \mathrm{~Pb}$ dos blocos lidos define-se a idade de cada etapa de aquecimento. Para o cálculo das idades ${ }^{207} \mathrm{~Pb} /{ }^{06} \mathrm{~Pb}$ foram utilizadas as constantes de Steiger \& Jäger (1977), sendo a precisão calculada para 2 sigmas ( $95 \%)$.

SÍTIO MINERALIZADO Geologia e Petrografia O sítio mineralizado em sodalita azul, explotado como rocha ornamental pela empresa ITABLUE localiza-se no interior do biotita-nefelinasienito e constitui um dique pegmatítico que chega a alcançar a espessura máxima de $3 \mathrm{~m}$. O esquema geológico (Fig. 3) e a figura 4 apresentam as relações de contato entre as diversas rochas e as principais texturas macroscópicas observadas em campo.

O biotita-nefelina-sienito encaixante da mineralização apresenta cor banca acinzentada, granulação média a grossa e uma foliação magmática $\left(\mathrm{N} 52^{\circ} 62^{\circ} \mathrm{SW}\right)$ que orienta os prismas de feldspato alcalino e as concentrações de minerais máficos. Os cristais de feldspato alcalino são pertíticos e incluem cristais euédricos de biotita, subédricos a anédricos de aegirina e subédricos de minerais opacos. As concentrações de minerais máficos reúnem cristais subédricos de biotita, hornblenda, magnetita, anédricos de pirita e, ocasionalmente, contêm calcita e fluorita.

Várias gerações de diques pegmatíticos foram identificadas na área da pedreira (Figs. 3 e 4). As mais antigas correspondem a hornblenda-nefelina-sienito e leuco-nefelina-sienito. Os diques de hornblenda-nefelina-sienito são corpos tabulares e contêm cristais centimétricos de hornblenda (até $2,6 \mathrm{~cm}$ ), com ocorrência limitada aos contatos, e cristais de nefelina verde, mais abundantes em sua região central (Fig. 4A). As relações texturais indicam que a nefelina cristalizou-se nos interstícios dos cristais prismáticos

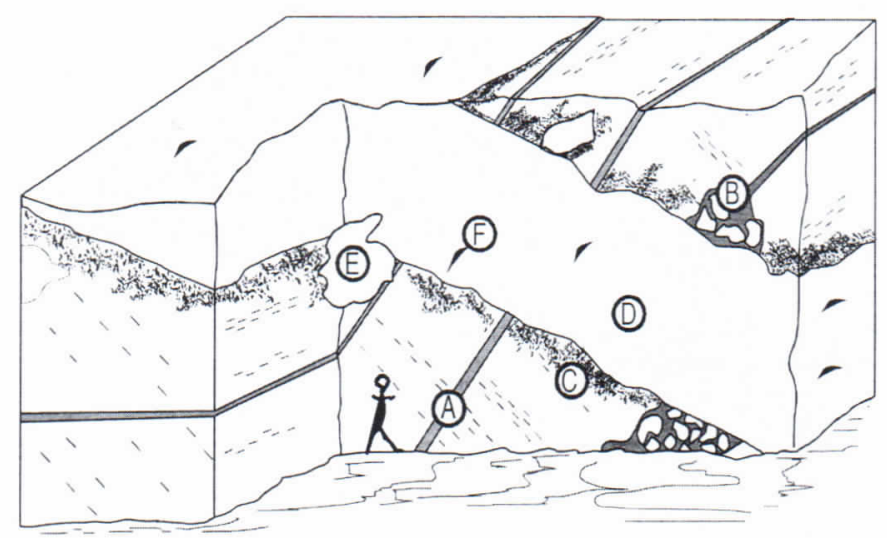

Figura 3 - Esquema geológico do dique mineralizado em sodalitasienito de cor azul. A forma humana estilizada tem 1,65 m de altura. As letras correspondem as indicações dos locais onde foram tiradas as fotografias apresentadas na figura 4. 

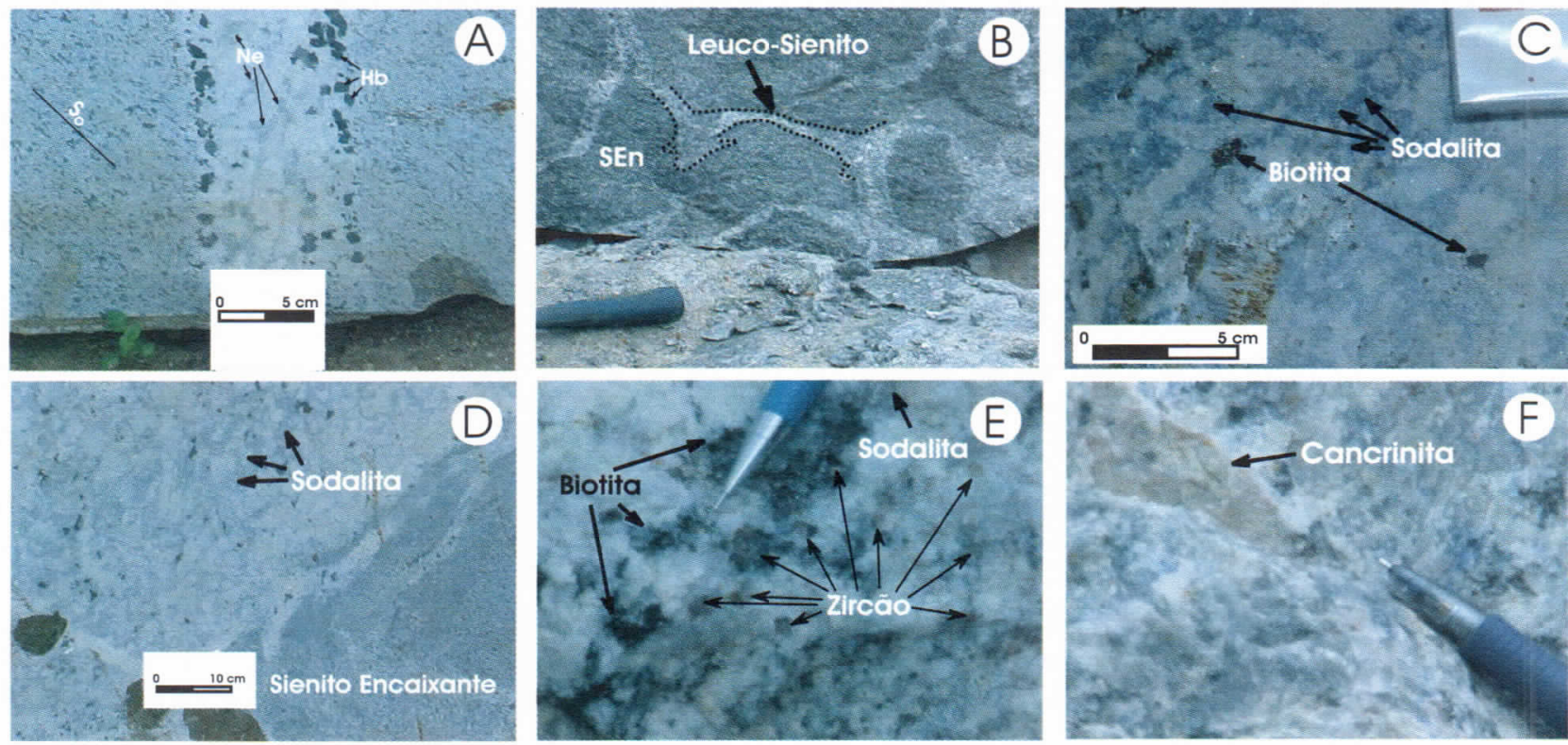

Figura 4 - Fotografias das regiões indicadas pelas letras A a F na figura 3. Dique de hornblenda-nefelina-sienito, com grandes cristais de nefelina $(\mathrm{Ne})$ e hormblenda $(\mathrm{Hb})$ com indicação da foliação magmática (So) do biotita-nefelina-sienito encaixante [A]. Dique de sienito leucocrático intrusivo nos biotita-nefelina-sienito encaixante [SEn] [B]. Região do sienito encaixante afetada por fluidos oriundos do dique de sodalita-sienito de cor azul; os grandes cristais de sodalita e de biotita são indicados pelas setas e os feldspatos alcalinos apresentam-se com tonalidade clara [C]. Região interna, com textura pegmatítica, do dique de sodalita-sienito de cor azul, sendo os cristais de sodalita (cor cinza escura), biotita (cor preta) e de feldspato alcalino (cor branca) [D]. Bolsão sienítico com sodalita e textura pegmatítica onde são indicados com setas os cristais centimétricos de zircão, sodalita e de biotita [E]. Vênula de cancrinita $[F]$.

de feldspato potássico pertítico e albita antipertítica. Os diques de leuco-nefelina-sienito apresentam espessuras não superiores a 5 $\mathrm{cm}$ e a sua idade relativa não pode ser estabelecida com os diques anteriormente descritos. Eles são constituídos por feldspato alcalino pertítico, nefelina, cancrinita, calcita e, de forma subordinada, fluorita. Cristais de titatina são ocasionais. As relações geométricas existentes entre este dique com os sienitos encaixantes apontam para a existência de fenômeno de brechação (Fig. 4B).

O dique sienítico mineralizado em sodalita azul (Fig 4C) é uma rocha com granulação variável (média a grossa) na qual o volume de sodalita chega a atingir 40\%. A distribuição relativamente homogênea da sodalita nesta rocha é o que lhe confere o valor comercial. Este dique é constituído essencialmente por feldspato alcalino pertítico, albita antipertítica, sodalita, nefelina e biotita, tendo como minerais acessórios aegirina, cancrinita, calcita, zircão, fluorita e minerais opacos. A sua colocação provoca transformações metassomáticas nas rochas sieníticas encaixantes. Macroscopicamente observa-se que a rocha sienítica encaixante perde a sua tonalidade original, adquirindo cor esbranquiçada e aparecem cristais de sodalita azul (Fig. 4D). Ao microscópio constata-se a presença de texturas de substituição nos minerais do sienito encaixante que foram interpretadas como a ação dos fluidos metassomáticos provenientes do dique. Com o aumento do metassomatismo, os feldspatos alcalinos são substituídos parcialmente pela sodalita e, nas fases finais deste processo, a cancrinita e calcita substituem ocasionalmente a sodalita. A biotita permanece na rocha após o metassomatismo, mas adquire uma cor marrom mais forte, sugerindo que sofreu igualmente a ação destes fluidos peralcalinos e ricos em cloreto. A atuação deste metassomatismo faz aparecer nas rochas transformadas uma textura poligonizada inexistente nas rochas sieníticas encaixantes. Lateralmente nas encaixantes e internamente ao dique de sodalita-sienito azul têmse bolsões pegmatíticos de coloração esbranquiçada. Dois conjuntos principais de bolsões pegmatíticos foram identificados. O primeiro corresponde à biotita-sodalita-sienito e ocorre tanto nos contatos quanto no interior do dique de sodalita azul. Ele é constituído essencialmente por feldspatos alcalinos pertíticos e antipertíticos, o máfico dominante é a biotita, tem-se sodalita e cristais centimétricos de zircão com até $4 \mathrm{~cm}$ (Fig. 4E). O segundo tipo de bolsão, desprovido de cristais de zircão, corresponde a sodalita-sienitos com especularita e com grandes agregados de cristais de sodalita. Vênulas tardias com espessuras centimétricas (2 até $4 \mathrm{~cm}$ ) são presentes, apresentam distribuição aleatória e cortam indistintamente os diques descritos, os bolsões e o sienito encaixante. O tipo mais abundante de vênula preenchido essencialmente por cancrinita (Fig. 4F), macroscopicamente de cor rósea, calcita e, mais raramente, fluorita.

Litogeoquímica Foram realizadas 6 análises químicas de rochas para este estudo. Duas são de sienitos encaixantes, sendo uma de sienito sem efeitos de metassomatismo visíveis a exame microscópico (2033) e outra com efeitos de metassomatismo identificado por substituição de minerais (2032). Três outras amostras (202I, 2030, 2034) correspondem a rochas faneríticas do dique de sodalitasienito. A amostra 2035 é de bolsão sienítico com cristais de sodalita e zircão. Na tabela 1 são listados os dados químicos obtidos.

As rochas estudadas apresentam estreita variação de $\mathrm{SiO}_{2}$ (53-58\%), $\mathrm{Al}_{2} \mathrm{O}_{3}$ (18-23\%), conteúdo em álcalis $\left(\mathrm{Na}_{2} \mathrm{O}+\mathrm{K}_{2} \mathrm{O}\right) \mathrm{com}-$ preendido entre $8 \%$ e $16 \%$, razão $\mathrm{Na}_{2} \mathrm{O} / \mathrm{K}_{2} \mathrm{O}$ variando de 1,3 até 1,84 , são dominantemente meteluminosas e a presença de sodalita 
em algumas das rochas estudadas é indicada pelo elevado conteúdo em $\mathrm{Cl}(>5.000$ ppm).

A rocha sienítica encaixante 2033 , sem efeitos visíveis de transformação, diferencia-se das demais rochas (Tabela 1) pelos conteúdos mais baixos em $\mathrm{Al}_{2} \mathrm{O}_{3}$ ( $\left.18,9 \%\right), \mathrm{Na}_{2} \mathrm{O}(5,6 \%), \mathrm{K}_{2} \mathrm{O}(3,2 \%)$, $\mathrm{CO}_{2}(0,79 \%), \mathrm{Ga}(18 \mathrm{ppm}), \mathrm{Nb}(132 \mathrm{ppm}), \mathrm{Zr}(159 \mathrm{ppm}), \mathrm{Y}(23 \mathrm{ppm})$, $\mathrm{Rb}(115 \mathrm{ppm})$ e altos valores de $\mathrm{TiO}_{2}(1,3 \%), \mathrm{FeO}(3,7 \%), \mathrm{MgO}$ ( $1,6 \%), \mathrm{P}_{2} \mathrm{O}_{5}(0,61 \%), \mathrm{Ba}(5750 \mathrm{ppm}), \mathrm{Sr}(2235 \mathrm{ppm})$ e S (287 ppm). Comparando-se com a análise desta rocha com a do sienito encaixante que exibe transtormação (Tabela 1), aqui interpretados

Tabela I - Análises químicas das rochas sieníticas estudadas Médlai 10 amostras) de biotita-nefélina sienitos (Média). A ras̃o La $/ Y b_{N}$ normalizadas ao Condrito $C 1$ de Evesen et al. (1978) e os parâmetros $\mathrm{ANK}=\left[\mathrm{Al}, \mathrm{O} f\left(\mathrm{Na}_{2} \mathrm{O}+\mathrm{K}_{2} \mathrm{O}\right)\right] \mathrm{e} A N K \mathrm{C}=\left[\mathrm{Al}_{2} \mathrm{O} /\right.$ $\left.\left(\mathrm{Na}{ }_{2} \mathrm{O}+\mathrm{K}_{2} \mathrm{O}+\mathrm{CaO}\right)\right]$ em moles.

\begin{tabular}{|c|c|c|c|c|c|c|c|}
\hline & Média & 2033 & 2032 & 2021 & 2034 & 2030 & 2035 \\
\hline $\mathrm{SiO}_{2}$ & 58.30 & 56.5 & 56,6 & 53,6 & 56,0 & 57,6 & 55,6 \\
\hline $\mathrm{Al}_{2} \mathrm{O}_{3}$ & 19.23 & 18.9 & 21.6 & 21.4 & 21.2 & 23.5 & 21.6 \\
\hline $\mathrm{TiO}_{2}$ & 0,74 & 1,3 & 0,21 & 0,26 & 0,35 & 0,16 & 0,24 \\
\hline $\mathrm{Fe}_{2} \mathrm{O}_{3}$ & 1,30 & 2,1 & 0,86 & 1,3 & 2,3 & 1,7 & 2,3 \\
\hline $\mathrm{eO}$ & 3,29 & 3,7 & 1,1 & 2,8 & 2,4 & 0,57 & 2,3 \\
\hline $\operatorname{lgO}$ & 0,82 & 1,6 & 0,14 & 0,33 & 0,67 & 0,12 & 0,56 \\
\hline $\mathrm{MnO}$ & 0,15 & 0,15 & 0,07 & 0,18 & 0,24 & 0,09 & 0,21 \\
\hline $\mathrm{aO}$ & 2,00 & 4,2 & 5,5 & 1,1 & 1,9 & 0,87 & 1,1 \\
\hline $\mathrm{a}_{2} \mathrm{O}$ & 6,90 & 5,6 & 6,0 & 9,6 & 6,9 & 9,4 & 8,1 \\
\hline $2 \mathrm{O}$ & 5,31 & 3,2 & 3,9 & 5,9 & 4,7 & 5,1 & 5,0 \\
\hline $\mathrm{P}_{2} \mathrm{O}_{5}$ & 0,29 & 0,61 & 0,05 & 0,08 & 0,18 & 0,02 & 0,01 \\
\hline${ }_{2} \mathrm{O}^{+}$ & 0,56 & 0.78 & 2.21 & 0,66 & 1,3 & 0,49 & 0.74 \\
\hline $\mathrm{O}^{\circ}$ & 0.25 & 0,01 & 0.18 & 0.32 & 0,5 & 0,14 & 0,25 \\
\hline $\mathrm{O}_{2}$ & 0,45 & $(0,74)$ & 1,08 & 0,82 & 1,39 & 1,51 & 2,91 \\
\hline Cutal & $99,+4$ & 99,43 & 99,49 & 98,35 & 100,03 & 101,27 & 100,92 \\
\hline $\mathrm{F}$ & 550 & 680) & 150 & 600 & 1100 & 96 & 1200 \\
\hline Co & 5 & 5 & 6 & 5 & 8 & 6 & 7 \\
\hline iu & 6 & 4 & 5 & 5 & 6 & 7 & 6 \\
\hline b & $<5$ & $<5$ & 13 & 5 & 22 & 5 & 22 \\
\hline $\mathrm{Ba}$ & 5980 & 5750 & 2098 & $50)$ & $7(0) 3$ & 787 & 643 \\
\hline 1 & 270 & 267 & 154 & 5000 & 5000 & $>5000$ & 5000 \\
\hline ;il & 26 & 18 & 36 & 36 & 45 & 49 & 52 \\
\hline $\mathrm{Hi}$ & I1 & $<8$ & 11 & 25 & 55 & 35 & 141 \\
\hline $\mathrm{Nb}$ & 115 & 32 & 291 & 161 & 483 & 355 & 1372 \\
\hline $\mathrm{Rb}$ & 1 & $<5$ & 162 & 389 & 260 & 47 & 327 \\
\hline & 184 & 287 & 106 & 86 & 89 & 131 & 82 \\
\hline $\mathrm{Sr}$ & 872 & 2235 & 1909 & 181 & 476 & 252 & 295 \\
\hline Ta & 11 & $<5$ & 25 & 11 & 51 & 10 & 169 \\
\hline Th & 20) & $<5$ & $<5$ & 22 & 78 & 42 & 117 \\
\hline U & $<10$ & $<10$ & 12 & $<10$ & 26 & 25 & 74 \\
\hline Y & 37 & 23 & 33 & 50 & 105 & 39 & 71 \\
\hline $\mathrm{Zr}$ & 466 & 159 & 416 & 08 & 2154 & 1341 & $>5000$ \\
\hline a & .22 & 45 & 4 & 7 &, 2 & 49,1 & 73,42 \\
\hline $\mathrm{Ce}$ & 76.72 & 63,76 & 55.69 & 9,19 & 210,2 & 80,45 & 155,2 \\
\hline $\mathrm{Nd}$ & 28,28 & 27,6 & 12,46 & 21,21 & 68,61 & 18,915 & 49,49 \\
\hline $\mathrm{Sm}$ & 5,16 & 5,026 & 98 & 156 & 14,8 & 3,546 & 9,849 \\
\hline Eu & 34 & 4 & 6 & 23 & 87 & 78 & 1,503 \\
\hline Gid & +2 & & & 893 & 11.55 & 2.457 & 6.58 \\
\hline Dy & 1.85 & $2,(127$ & 39 & 36 & 8,5 & 1.425 & 4.698 \\
\hline Ho & 35 & & & 0,388 & 609 & 0,245 & 0,823 \\
\hline Er & 33 & 0,707 & 5 & 0.891 & 6 & 0,611 & 1,705 \\
\hline Yb & 0,47 & 0,43 & 0,218 & 0,63 & 2,773 & 0,429 & 1,109 \\
\hline Lu & $(0,11$ & 0,063 & $0,(042$ & 0,113 & 0,369 & ().(092 & 0,151 \\
\hline Total & 163,56 & 144,425 & 112,227 & 136.5 & 433,884 & 157,948 & 304,528 \\
\hline $\mathrm{Na}_{2} \mathrm{O}+$ & 12,2 & 8,8 & 9.9 & 15.5 & 11,6 & 14,5 & 13,1 \\
\hline $\mathrm{Ni}_{2} \mathrm{O} / \mathrm{K}_{2} \mathrm{O}$ & 1.3 & 1,75 & 1,54 & 1,63 & 1,47 & 1,84 & 1,62 \\
\hline $\mathrm{Eu} / \mathrm{Eu} *$ & & 2,42 & 1,12 & 0,61 & 0,49 & 0,67 & 0,54 \\
\hline$|\mathrm{Lia} / \mathrm{Yb}|_{\mathrm{N}}$ & & 58,89 & 18,93 & 36,89 & 26,63 & 77,40 & 44,77 \\
\hline ANK & & 1,49 & 1.53 & 0,96 & 1,28 & 1,12 & 1,15 \\
\hline ANKC & & 0,93 & 0,89 & 0,88 & 1,06 & 1,04 & 1,04 \\
\hline
\end{tabular}

como devido a colocação do dique mineralizado em sodalita, constata-se que existe aumento de $\mathrm{Na}_{2} \mathrm{O}, \mathrm{K}_{2} \mathrm{O}, \mathrm{Al}_{2} \mathrm{O}_{3}, \mathrm{Ga}, \mathrm{Nb}, \mathrm{Rb}, \mathrm{Ta}, \mathrm{U}$, $\mathrm{Y}$ e Zr, que é seguido pela diminuição dos conteúdos de $\mathrm{P}_{2} \mathrm{O}_{5}, \mathrm{Ba}$ e $\mathrm{Sr}$ (Fig. 5A). Diferenças entre estas duas amostras são igualmente perceptíveis nos conteúdos dos ETR (Tabela 1) e se marcam pela anomalia positiva em $\mathrm{Eu}(2,42 \rightarrow 1,12$, Fig. $6 \mathrm{~A})$ e pelo aumento na razão $(\mathrm{La} / \mathrm{Yb}) \mathrm{N}(58 \rightarrow 118$, Tabela 1$)$.

As três amostras do dique mineralizado em sodalita (2021, 2030, 2034) apresentam importante variação no conteúdo em álcalis (Tabela 1), pequena variação em $\mathrm{Al}_{2} \mathrm{O}_{3}(21-23 \%)$ e razão $\mathrm{Na}_{2} \mathrm{O} / \mathrm{K}_{2} \mathrm{O}$

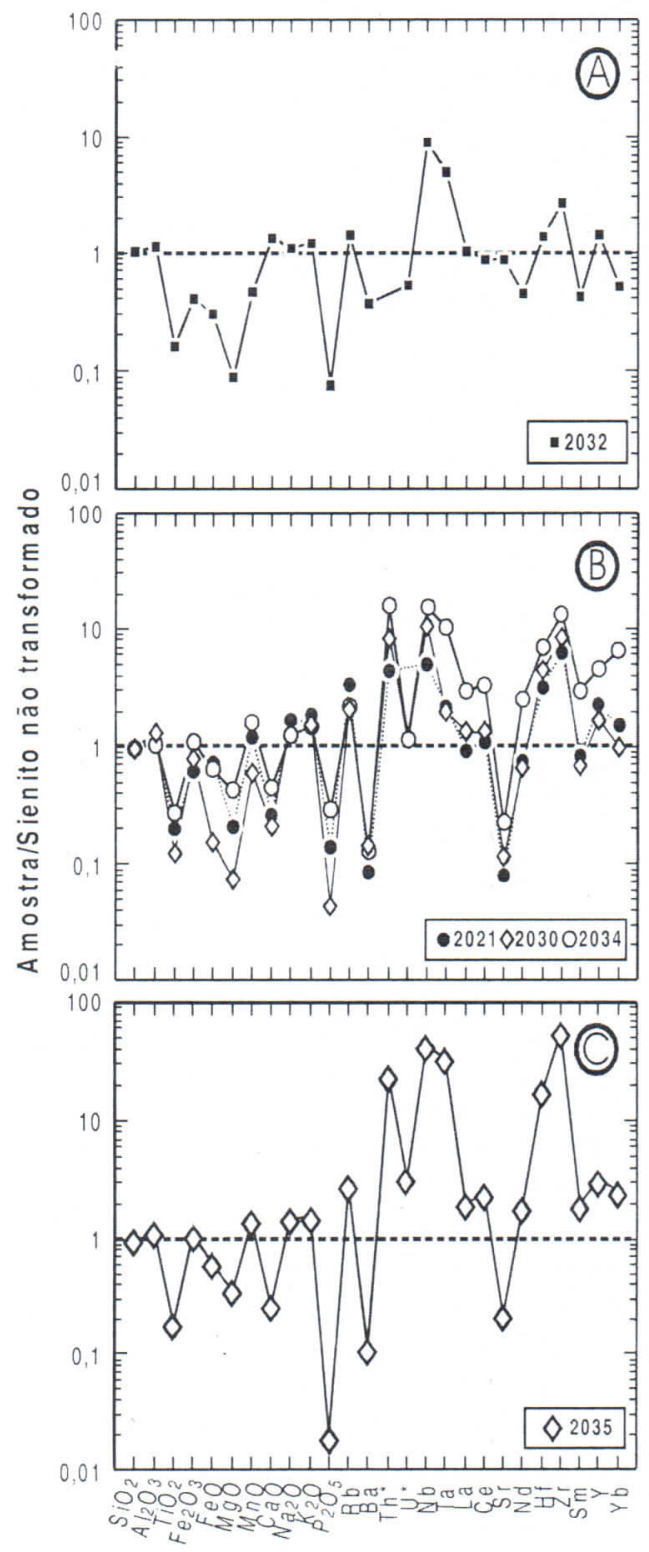

Figura 5 - Diagramas multielementares das rochas estudadas normalizados pela amostra do biotita-nefelina-sienito encaixante não afetado pelo metassomatismo (2033). Sienito encaixante transformado $[A]$, rochas do dique de sodalita-sienito de cor azul [B] e bolsão de sodalita-sienito com cristais de zircão [C]. Os asteriscos no Th e U indicam que se utilizou os valores de 5 ppme 10 ppm para a normalização e estes valores correspondem ao limite de detecção destes elementos. 
compreendida entre 1,5 e 2,0. Os espectros destas rochas, normalizados pelo sienito sem evidências de alteração, são caracterizados pelo enriquecimento importante em Th, Nbe Zr (Fig. 5B). Os espectros dos ETR são marcados por anomalias em Eu (Fig. 6B) e variáveis razões $(\mathrm{La} / \mathrm{Yb})_{\mathrm{N}}$, compreendidas entre 26 e 77.

A amostra do bolsão sienítico com sodalita e zircão destaca-se das do dique sienítico com sodalita (Tab. I) pelos elevados conteúdos em Zr (>5.000 ppm), Hf (14l ppm), Ta (169 ppm), Th (117 ppm), U (74 ppm) e F (1200 ppm). A curva obtida com a normalização pelo sienito sem evidências de alteração (Fig. 5B) e o espectro dos ETR (Fig. 6C) desta rocha são similares aos encontrados no dique sienítico com sodalita, indicando cogeneticidade.

Ordem de cristalização e tipologia dos cristais de zircão Os cristais de zircão analisados nas amostras 2034 e 2035 constituem uma população uniforme com cor castanha escura avermelhada e hábito caracterizado por prisma longo. Ao microscópio, não apresentam evidências de alteração e ocorrem com tamanhos variando de $1 \mathrm{~mm}$ até $4 \mathrm{~cm}$. As texturas observadas indicam que o zircão cristaliza-se após o feldspato alcalino pertítico e antes da biotita, albita e sodalita. As fraturas presentes nestes cristais são sem preenchimento e afetam igualmente os outros minerais da rocha indicando seu caráter tardio.

Uma população constituída por cristais bem formados (4 da amostra 2034 e 10 da amostra 2035), com tamanhos em torno de 1 $\mathrm{cm}$, foi analisada visando classificá-los segundo a tipologia proposta por Pupin (1980). Nesta população, identificou-se a existência de cristais dos tipos D e K1, com dominância do tipo D que, segundo Pupin \& Turgo (1975), são característicos de rochas sieníticas sub-saturadas.

Idade $\mathrm{Pb}-\mathrm{Pb} \quad \mathrm{Na}$ amostra 2034 foram analisados 8 fragmentos de cristais de zircão castanho-claro a escuro, com granulação entre 0,2 e $0,5 \mathrm{~mm}$, translúcidos e sem inclusões. Entretanto, apenas 5 deles emitiram $\mathrm{Pb}$ suficiente para análise (Tabela 2). Os resultados obtidos forneceram uma idade de $720 \pm 9$ Ma (Fig. 7).

$\mathrm{Na}$ amostra 2035 foram analisados nove fragmentos de zircão de coloração castanha clara, com tamanhos compreendidos entre $0,1 \mathrm{~mm}$ e $0,6 \mathrm{~mm}$, transparentes, translúcidos e sem apresentarem fraturas e inclusões. Destes, os fragmentos de números 3, 6 e 7 não emitiram $\mathrm{Pb}$ suficientes para análise. Os resultados obtidos do fragmento 8 foram descartados por apresentarem altos valores de $\mathrm{Pb}$ comum. Os outros seis forneceram um total de 9 blocos, dos quais foram descartados 4 (Tabela 2, Fig. 8). A idade calculada utilizando-se os blocos válidos foi de $732 \pm 24$ Ma.

Os resultados geocronológicos obtidos para as duas amostras analisadas mostram uma superposição de idades (711 - 729 $\mathrm{Ma}$ ), sendo este intervalo aqui considerado como a idade mínima de cristalização da mineralização em sodalita-sienito azul.

DISCUSSÃO E CONCLUSÕES Comparando-se as idades encontradas para a cristalização do Maciço Nefelina-Sienítico Itarantim $(727 \pm 30 \mathrm{Ma})$ com a da cristalização do sienito mineralizado em sodalita azul ( $720 \pm 9$ Ma e $732 \pm 24 \mathrm{Ma})$ constatase, considerando-se os erros envolvidos nestas determinações, que as formações destas rochas foram contemporâneas. Neste contexto, as idades mais novas obtidas por Cordani et al. (1974)e Bernat et al. (1977) para as rochas deste mesmo maciço refletem, provavelmente, perturbações nos sistemas isotópicos $\mathrm{K}$-Ar e ArAr nos minerais datados por eventos posteriores. As idades cambrianas obtidas por estes autores, situadas entre 520-546 Ma,
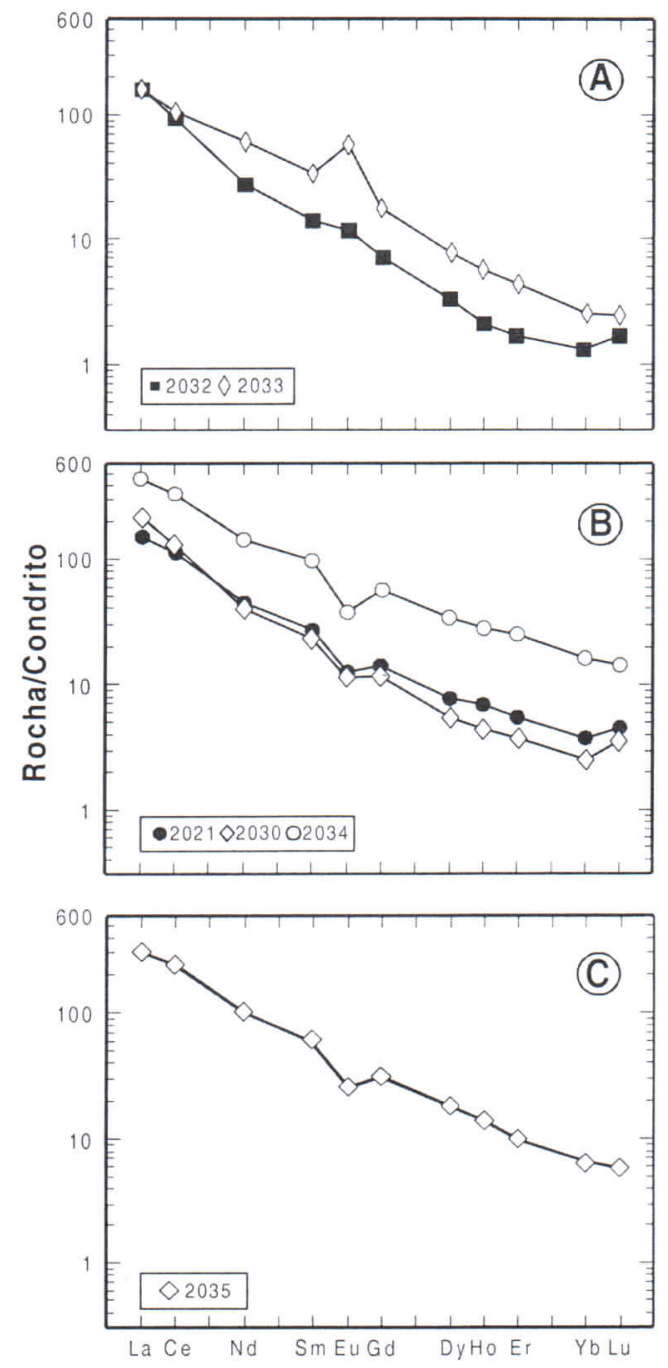

Figura 6 - Diagramas dos Elementos Terras Raras para as rochas estudadas normalizado pelo Condrito C1 de Evesen et al. (1978). Sienitos encaixantes [A], dique de sodalita-sienito [B] e sodalitasienito com cristais de zircão [C].

podem traduzir os efeitos tardios da colisão Araçuaí, localizada a sudoeste, que, segundo Pedrosa Soares et al. (2001), tem seu clímax em 550 Ma. As idades ordovincianas (474-485 Ma) são de difícil interpretação a luz dos dados disponíveis.

A disposição em dique do sodalita-sienito de cor azul presente no biotita-nefelina-sienito, sugere que o sienito azul representa um dos produtos gerados durante a diferenciação do magma responsável pela formação das rochas do Maciço NefelinaSienítico Itarantim. A existência de importante área de fenitos coroando o maciço aponta para uma expressiva riqueza em fluidos deste magma. Por outro lado, a cristalização de feldspatos e o baixo volume de minerais hidratados formados durante a cristalização destas rochas - menor que $8 \%$ em volume segundo Oliveira (2003)-, sugerem que os produtos diferenciados da evolução do magma Itarantim tendem a ser enriquecidos em componentes voláteis. As presenças de sienitos com textura pegmatítica e de grandes cristais encontrados em muitos diques alcalinos presentes são a favor desta hipótese.

A existência de contatos retilíneos e nítidos entre o dique de 
Tabela 2 - Resultados analíticos obtidos pelo método Pb-Pb das amostras 2034 e 2035, rochas sodalita-sieníticas do sítio mineralizado estudado. Etapa de evaporação eliminada subjetivamente [*], razão ${ }^{207} \mathrm{~Pb} /{ }^{206} \mathrm{~Pb}$ corrigida para contaminação do $\mathrm{Pb}$ comum [**]].

\begin{tabular}{|c|c|c|c|c|c|c|c|}
\hline Zircão & Temp. ("C) & ${ }^{0.07} \mathrm{~Pb} /{ }^{206} \mathrm{~Pb}$ & $2 \sigma$ & $\left.{ }^{207} \mathrm{~Pb} /{ }^{206} \mathrm{~Pb}\right)^{\text {*** }}$ & $2 \sigma$ & Idade (Ma) & $2 \sigma$ \\
\hline \multirow[t]{2}{*}{$2(034 / 2$} & $* 1500$ & 0,06539 & 41 & 0,06322 & 63 & 716 & 21 \\
\hline & 1600 & $0,06+21$ & 56 & $0,(06339$ & 16 & 721 & 5 \\
\hline \multirow[t]{2}{*}{$2034 / 3$} & $* 1500$ & 0,07143 & 34 & 0,06119 & 99 & 646 & 35 \\
\hline & 1600 & 0,07382 & 56 & 0,06240 & 47 & 688 & 16 \\
\hline $2013+1 / 4$ & 1500 & 0.08495 & 17 & 0.06 .373 & 63 & 73.3 & 21 \\
\hline $2(1) 34 / 6$ & 1450 & 0,06866 & 27 & 0,06326 & 38 & 717 & 13 \\
\hline \multirow[t]{3}{*}{$2034 / 8$} & $* 1500$ & 0,06607 & 56 & 0,06031 & 199 & 615 & 71 \\
\hline & $* 1585$ & 0,06931 & 43 & 0,06311 & 32 & 712 & 11 \\
\hline & 1620 & 0,06957 & 142 & 0,06355 & 32 & 727 & 11 \\
\hline \multirow[t]{3}{*}{$2035 / 1$} & $* 1450$ & 0,09816 & 59 & 0,05998 & 275 & 603 & 99 \\
\hline & $* 1500$ & 0,07733 & 109 & 0,06114 & 112 & 644 & 39 \\
\hline & 1550 & 0,08666 & 46 & 0,06253 & 65 & 693 & 22 \\
\hline 2() $35 / 2$ & 1600 & 0.09333 & 183 & 0,06315 & 196 & 714 & 66 \\
\hline $2035 / 4$ & 1500 & 0,11445 & 29) & 0,06577 & 138 & 799 & 44 \\
\hline $2035 / 5$ & 1550 & 0.06545 & 41 & 0.06355 & 67 & 727 & 22 \\
\hline 2() $35 / 7$ & $* 1700$ & 0.08405 & 36 & 0,06121 & 22 & 647 & 8 \\
\hline \multirow[t]{3}{*}{$2(135 / 9$} & $* 1500$ & 0,06388 & 19 & 0,06222 & 50) & 682 & 17 \\
\hline & 155() & 0.06 .546 & 50 & 0.06409 & 45 & 745 & 15 \\
\hline & $" 1600$ & 0,06877 & 42 & 0,06877 & 42 & 892 & 13 \\
\hline
\end{tabular}

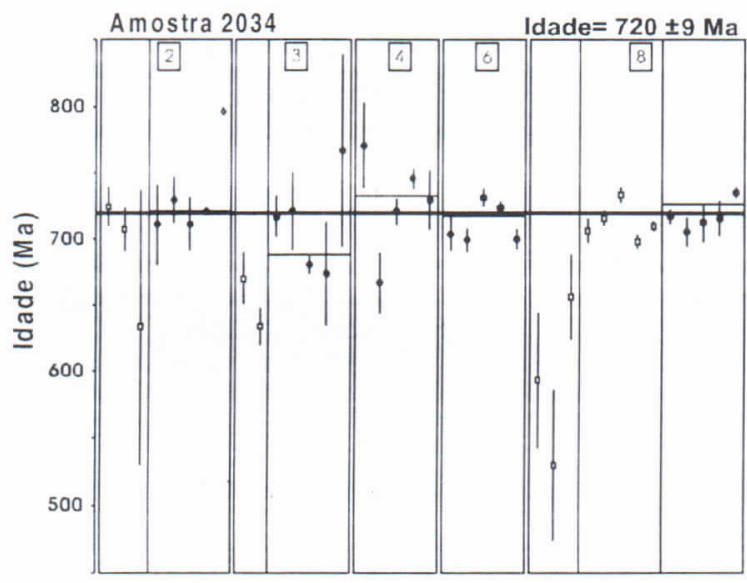

Etapas de Aquecimento

Figura 7 - Diagramas Etapas de Aquecimento versus Idade para a anostra 2034. Círculo cheio corresponde aos blocos analíticos utilizados no cálculo da idade; quadrado as etapas de evaporação eliminadas subjetivamente.

sienito azul, que trunca a foliação magmática do sienito encaixante, indica que esta já se apresentava, se não totalmente cristalizado, com alto percentual de cristais ( $>80 \%$ de cristais). Este fato é condizente com os dados experimentais disponíveis na literatura, que apontam temperaturas da ordem de $800-900^{\circ} \mathrm{C}$ para cristalização de nefelina-sienitos (MacDowell \& Wyllie 1971) e de $400-800^{\circ} \mathrm{C}$ para a cristalização da sodálita (Deer et al. 1996). Por outro lado, os estudos experimentais realizados por Wellman (1970) colocaram em evidência que, quando a sodalita coexiste com nefelina e dois feldspatos. como é o caso do dique estudado, as temperaturas de cristalização situam-se entre $500^{\circ} \mathrm{C}$ e $600^{\circ} \mathrm{C}$.

A presença de efeito metassomático nas rochas sieníticas em

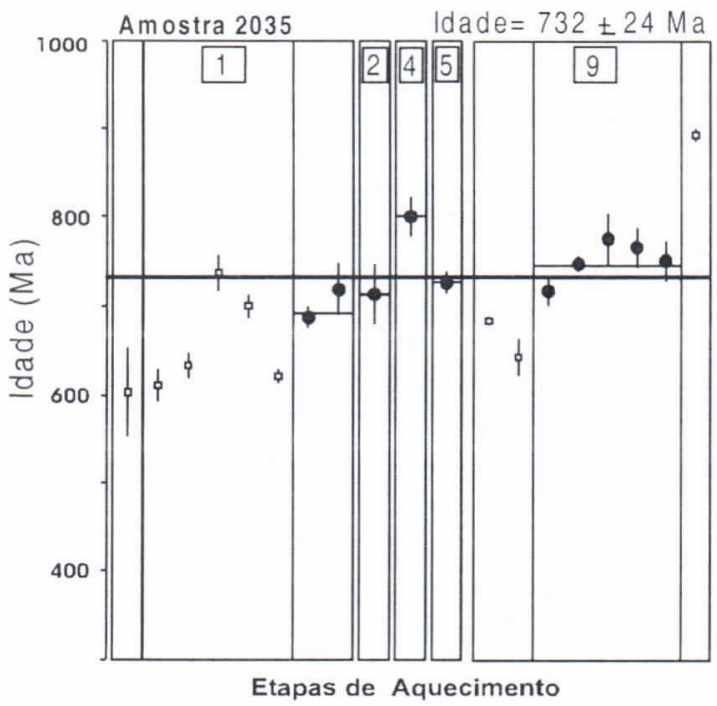

Figura 8 - Diagramas Etapas de Aquecimento versus Idade para a amostra e 2035. Círculos cheios correspondem aos blocos analíticos utilizados no cálculo da idade; quadrado as etapas de evaporação eliminadas subjetivamente.

contato revela a existência de desequilíbrio físico-químico entre o magma pegmatítico e as encaixantes sieníticas. Este metassomatismo peralcalino e rico em cloro (sodalita tem até $8 \%$ $\mathrm{Cl}_{2}$ ), afeta as encaixantes aportando álcalis e muitos dos elementos normalmente considerados imóveis (e.g. Nb, Ta, U, Y, Th, Zr), tendose igualmente o empobrecimento em Ba, Sr e ETR, particularmente o Eu (Fig. 6).

As rochas nefelina-sieníticas do MNSI não têm cristais de zircão e seus conteúdos em Zr são inferiores a 600 ppm (Oliveira 2003). Este fato é relativamente comum nos magmas peralcalinos sub-saturados em $\mathrm{SiO}_{2}$, onde $\mathrm{Zr}$, devido aos valores da razão $\mathrm{Al} /$ $\mathrm{Na}+\mathrm{K}>1$ no magma, não atinge a saturação necessária para impor a cristalização do zircão (Watson 1979), sendo o Zr normalmente incorporado à estrutura dos piroxênios alcalinos (Jones \& Peckett 1980). Desta forma, o Zr permanece no magma até os diferenciados finais onde pode se cristalizar sob a forma de zircão ou de zirconossilicatos complexos. Os elevados valores de $\mathrm{Zr}(>1000$ ppm) nos sienitos com sodalita estudados associados a presença de cristais de zircão são evidências consideradas suficientes para caracterizar a saturação de $\mathrm{Zr}$ neste magma pegmatítico.

Em resumo, a idade da mineralização em sodalita azul no Maciço Nefelina-Sienítico Itarantim está compreendida entre $720 \pm 9$ Ma e $732 \pm 24$ Ma e estas rochas (dique e bolsão sienítico com sodalita) representam, provavelmente, a expressão de termos diferenciados, particularmente enriquecidos em $\mathrm{Cl}$ e $\mathrm{Zr}$ capazes de estabilizarem as cristalizações da sodalita e do zircão.

Agradecimentos O estudo das rochas da Província Alcalina do Sul do Estado da Bahia está sendo desenvolvido com o apoio do CNPq (Proc. 462916/00 e 479509/01-8) e da Companhia Baiana de Pesquisa Mineral - CBPM (Convênio CBPM/UFBA/FAPEX n ${ }^{\circ}$ 1460). M.L.S. Rosa agradece ao CNPq pela bolsa DCR (Proc. 30139/ 00) e à equipe do Pará-Iso pela acolhida durante o estágio em 2002. Aos revisores da RBG pelas sugestões ao manuscrito. Esta é a contribuição de número 142 do Grupo de Petrologia Aplicada à Pesquisa Mineral da UFBA. 


\section{Referências}

Barbosa de Deus P., Rangel P.A., Silveira W.P., Viana I.A., Alecrim J.D., Villas Boas A., Pamponet L.T.C., Araújo J.B., Rodrigues J.B., Cardoso P.C.S., Vasconcellos H.G., Garrido I.A.A., Ribeiro W., Bezerra A.T., Rego J.E., Silva N.S., Siqueira L.P., Bezerra J.C.L., Souto P.G. 1976. Textos e fichas petrográficas. In: Projeto Rochas Alcalinas de Itarantim - Fase I - SMECPM, Salvador, 160 p.

Bernat M., Cordani U.G., Kawashita K. 1977. Ages ${ }^{39} \mathrm{Ar} /{ }^{40} \mathrm{Ar}$ des massifs alcalins du sud de l'État de Bahia, Brésil. Cashiers ORSTOM, Série Géologie, 9:35-43.

Brito Neves B.B., Cordani U.G., Torquato J.R.F. 1980. Evolução geocronológica do Pré-Cambriano do Estado da Bahia. In: Inda H.A.V. \& Duarte F.B., Geologia e Recursos Minerais do Estado da Bahia, Textos Básicos, SME-CPM, 3:1-80.

Cordani U.G., Bernat M., Teixeira W., Kawashita H. 1974. Idades radiométricas das rochas alcalinas do Sul do Estado da Bahia. In: SBG Cong. Bras. Geol., 27, Porto Alegre, Anciis, 6:253-259

Corrêa Gomes L.C. 2000. Evolução dinâmica da Zona de Cisalhamento neoproterozóica de Itabuna-Itajú do Colônia e do magmatismo fissural alcalino associado (SSE do Estado da Bahia, Brasil). Inst. de Geociências, Universidade Estadual de Campinas, Tese de Doutoramento, $201 \mathrm{p}$.

Cunha M.P.. Rosa M.L.S.. Conceição H., Marinho M.M., Menezes R.C.L., Medeiros K.O.P., Brandão A.T. 2002. Sodalita-sienitos azuis da Província Alcalina do Sul do Estado da Bahia: aspectos litogeoquímicos. In: SBG Congr. Bras. Geol., 41, João Pessoa, Anais: 536.

Deer W.A., Howie R.A., Zussman J. 1996. An Introduction to the RockForming Minerals. Logman Scientific \& Technical, London. 696 p.

Evesen N.M.. Hamilton P.J.. O`Nions R.K. 1978. Rare earth abundances in chondrite meteorites. Geochim. Cosmoch. Acta, 42:1199-1212.

Fujimori S. 1978. Rochas alcalinas da fazenda Hiassu, Itajú do Colônia, Bahia. Publicação Especial da SBG-Núcleo Bahia-Sergipe, 2:117 p.

Jones A.P. \& Peckett A. 1980. Zirconium-bearing aegirines from Motzfeldt, South Greenland. Contrib. Mineral. Petrol., 75:251-255.

Köber B. 1987. Single grain evaporation combined with $\mathrm{Pb}$ emitter bedding ${ }^{207} \mathrm{~Pb} /{ }^{206} \mathrm{~Pb}$ ivestigations using thermal ion mass spectrometry and implications to zircolonogy. Contrib. Mineral. Petrol., 96:63:71.

Lima M.I.C., Fonsêca E.G., Oliveira E.P., Ghignone J.I., Rocha R.M., Carmo U.F., Silva J.M.R., Siga Jr. O. 1981. Geologia. In: Projeto RADAMBRASIL. Programa de Integração Nacional, Folha SD.24 Salvador, 24:24-192.

McDowell S.D. \& Wyllie P.J. 1971. Experimental studies of igneous rocks series: The Kungnât Complex of Southwest Greenland. J. Geol. 79:173-194.

Martins A.A.M. \& Santos R.A. 1993. Ibicaraí, Folha SD.24-Y-B-V, escala 1:100.000. Programa de Levantamentos Geológicos Básico do Brasil. MME-SMM-DNPM, Brasília, 192 p.

Mascarenhas J.F. 1979. Evolução geotectônica do pré-cambriano do Estado da Bahia. In: Inda H.A.V. (ed). Geologia e Recursos Minerais do Estado da Bahia. Textos Básicos. SME-CPRM. 2:57-165.

Menezes R.C.L., Rosa M.L.S., Conceição H., Medeiros K.O.P., Cunha M.P., Jesus V.F., Marques L.S., Marinho M.M., Brandão A.T., Oliveira A.E.L. 2002. Geologia e petrografia dos sodalita-sienitos azuis do Maciço Nefelina-Sienítico Rio Pardo. In: Congr. Bras. Geol., 41, João Pessoa, Anais: 196.

Oliveira A.E.L. 2003. Geologia, Petrografia, Litogeoquímica e idade RbSr do Maciço Sienítico Itarantim, Sul do Estado da Bahia. Inst. de Geociências, Universidade Federal da Bahia, Dissertação de Mestrado, $110 \mathrm{p}$.

Pedrosa-Soares A.C., Noce C.M., Wiedmann C.M., Pinto C.P. 2001 The Araçuaí-West-Congo Orogen in Brazil: an overview of a confined orogen formed during Gondowanaland assembly. Precambrian Research 110:307-323.

Pupin J.-P. 1980. Zircon and Granite Petrology. Contrib. Mineral. Petrol., 73:207-220.

Pupin J.-P. \& Turgo G. 1975. Typologie du zircon accessoire dans les roches plutoniques dioritiques, granitiques et syénitiques. Facteurs essentiels déterminant les variations typologiques. Pétrologie 1:139156.

Rosa M.L.S., Conceição H., Macambira M.J.B., Marinho M.M., Marques L.S., Oliveira L.L. 2001. Idade (Pb-Pb), aspectos petrográficos e litogeoquímicos do Complexo alcalino Floresta azul (sul do estado da Bahia). Rev. Bras. Geociências, 33:13-20.

Rosa M.L.S., Conceição H., Marinho M.M., Macambira M.J.B., Marques L.S. 2002. Geochronology of the South Bahia Alkaline Province (NE Brazil). Geoch. Cosmoch. Acta, 66: A648

Silva Filho M.A., Moraes Filho O., Gil C.A.A. Santos R.A. 1976. Projeto Sul da Bahia, Folha SD.24-Y-D. Relatório Final, Convênio DNPMCPRM, 1:164 p.

Spínola V. 2003. Rochas ornamentais em arranjo produtivo. Superintendência de Estudos Econômicos e Sócias da Bahia. Série Estudos e Pesquisa, 121 p.

Steiger R.H. \& Jäger E. 1977. Subcommission on geochronology. Convention on the use of decay constants in geo and cosmochronology. Earth Planet. Sci. Letters, 36:359-362.

Teixeira W., Kamo S.L., Arcanjo J.B.A. 1997. U-Pb zircon and baddeleyte age and tectonic interpretation of the Itabuna alkaline suite. São Francisco Craton, Brazil. J. South Am. Earth Sci., 10:91-98.

Watson E.B. 1979. Zircon saturation in felsic liquids: experimental results and applications to trace element geochemistry. Contrib. Mineral. Petrol., 70:407-419.

Wellman T.R. 1970. The stability of sodalite in synthetic syenite plus aqueous chloride fluid system. J. Petrol. 11:49-71.

Manuscrito A-1403

Recebido em 08 de janeiro de 2003

Revisão dos autores em 01 de maio de 2004 Revisão aceita em 20 de maio de 2004 